\title{
Endocrine Treatment of Metastatic Breast Cancer
}

\author{
Bernd Gerber ${ }^{a^{*}}$ Jens Huober b* $^{*}$ \\ a Breast Unit, Department of Obstetrics and Gynecology, University of Rostock, \\ ${ }^{b}$ Department of Obstetrics and Gynecology, University of Tübingen, Germany
}

\section{Key Words}

Advanced breast cancer - Hormons - Tamoxifen .

Aromatase inhibitor · Fulvestrant

\section{Summary}

Endocrine treatment represents the first choice in the treatment of endocrine-responsive non-life-threatening advanced breast cancer. Hormone receptor expression can be ascertained either on the metastasis (if biopsy can be taken easily) or on the primary tumor. The selection of endocrine therapy takes into account the menopausal status of the patient, the type of previous adjuvant endocrine treatment, the diseasefree interval and past medical history. In premenopausal patients, the combination of LHRH (luteinizing hormone-releasing hormone) agonists and a second endocrine treatment (tamoxifen, anastrozole, fulvestrant, progestagens) is more effective than the single agents. In postmenopausal patients with recurrent disease progressing after or during adjuvant tamoxifen, third-generation aromatase inhibitors (Als) are the preferred first-line endocrine treatment. In second-line treatment, fulvestrant, a second Al or tamoxifen again are reasonable options. There is no cross-resistance between steroidal and non-steroidal anti-aromatase agents. Steroidal Als (exemestane) have shown activity after failure of non-steroidal Als (anastrozole, letrozole). Vice versa, patients receiving exemestane as first anti-aromatase agent may also benefit from letrozole or anastrozole after disease progression. Simultaneous endocrine and cytostatic therapy is not recommended because the combination induces increased toxicity and does not improve overall survival. Maintenance endocrine therapy following chemotherapy appears to improve relapse-free and overall survival.

\footnotetext{
*As members of the Breast Commission, part of the AGO (Working
Group Gynecologic Oncology, German Society of Obstetrics and Gyne-

*As members of the Breast Commission, part of the AGO (Working
Group Gynecologic Oncology, German Society of Obstetrics and Gynecology)
}

\author{
Schlüsselwörter \\ Metastasierter Brustkrebs · Hormone - Tamoxifen . \\ Aromatasehemmer · Fulvestrant
}

\section{Zusammenfassung}

Die endokrine Therapie ist die erste Therapieoption beim metastasierten/rezidivierten hormonsensitiven Mammakarzinom mit nicht lebensbedrohlicher Erkrankungssituation. Die Bestimmung der Hormonrezeptorexpression kann - falls leicht erreichbar - an der Metastase bzw. dem Rezidiv erfolgen. Die Bestimmung am Primärtumor ist jedoch ausreichend. Bei der Wahl der endokrinen Therapie müssen Menopausestatus, Vorbehandlung, krankheitsfreies Intervall und andere Risikofaktoren berücksichtigt werden. Bei prämenopausalen Patientinnen ist die Kombination eines LHRH (luteinizing hormonereleasing hormone)-Agonisten kombiniert mit einer zweiten endokrinen Therapie (Tamoxifen, Anastrozol, Fulvestrant, Gestagene) effektiver als diese Therapien alleine. Bei postmenopausalen Patientinnen mit Krankheitsrückfall unter/nach adjuvanter Tamoxifen-Gabe stellen Aromatasehemmer der 3. Generation den ersten endokrinen Therapieschritt dar. Für die Zweitlinientherapie sind Fulvestrant, ein weiterer Aromatasehemmer oder abermals Tamoxifen eine Option. Zwischen steroidalen (Exemestan) und nicht-steroidalen Antiaromatasehemmern (Anastrozol, Letrozol) besteht keine Kreuzresistenz, d. h. Exemestan ist nach Anastrozol und Letrozol wirksam bzw. umgekehrt. Eine simultane chemo-endokrine Therapie kann nicht empfohlen werden, da sie zu mehr Nebenwirkungen führt, ohne dass das Gesamtüberleben verlängert wird. Eine endokrine Erhaltungstherapie nach erfolgter Chemotherapie scheint das rezidivfreie und auch das Gesamtüberleben zu verbessern.

\begin{tabular}{ll}
\hline KARGER & ( 2006 S. Karger GmbH, Freiburg \\
$\begin{array}{l}\text { Fax +49 761 4520714 } \\
\begin{array}{l}\text { E-mail Information@Karger.de } \\
\text { www.karger.com }\end{array}\end{array}$ & Accessible online at: \\
& www.karger.com/brc \\
&
\end{tabular}

Prof. Dr. Bernd Gerber

Universitätsfrauenklinik und Poliklinik

am Klinikum Südstadt der Hansestadt Rostock

Südring 81,18055 Rostock, Germany

Tel. +49 381 4401-4500, Fax +49 381 4401-4599

E-mail bernd.gerber@med.uni-rostock.de 


\section{Basics of Endocrine Treatment}

Endocrine therapy remains the first choice and most important part in the treatment of hormone-sensitive non-lifethreatening advanced breast cancer. This approach has the advantage of combining efficacy, minimal toxicity, and good quality of life. However, a requirement for a successful endocrine therapy is a positive estrogen receptor (ER) and/or progesterone receptor (PR) status, either of the metastasis (if biopsy of the metastasis is possible and manageable) or of the primary tumor. One needs to consider that endocrine treatment takes 8-12 weeks to reveal a tumor response. The selection of the most appropriate endocrine therapy takes into account the menopausal status of the patient, the type of previous adjuvant endocrine treatment, the disease-free interval and the past medical history (e.g. thromboembolic disease). A meta-analysis of non-randomized observational trials suggests that HER2-positive metastatic breast cancer is less responsive to any type of endocrine treatment [1]. This issue is currently being addressed by the ELECTRA Study evaluating prospectively the efficacy of the aromatase inhibitor (AI) letrozole in metastatic hormone receptor-positive HER2-positive or negative breast cancer.

Response to endocrine therapy increases with the amount of ER and PR receptor-positive cells. The effectiveness of endocrine treatment is measured by improvement of clinical symptoms and/or tumor response. Quantitative $\left[{ }^{18} \mathrm{~F}\right]$ fluoroestradiol positron emission tomography (PET) or tumor markers can predict response to hormonal therapy and may help guide treatment selection [2]. Currently, there is no recommendation for routine use of PET or other diagnostic tools in monitoring endocrine therapy of advanced breast cancer. Patients responding to endocrine treatment should be treated until progression or occurrence of adverse effects. In the case of progression after long-lasting endocrine treatment, a further endocrine step is recommended. Early progress during endocrine treatment will usually require chemotherapy.

\section{Drugs}

All patients receiving endocrine treatment for advanced breast cancer will at some time progress, resulting in a need for new therapies that lack cross-resistance with existing agents. 3rd-generation aromatase agents are more effective than tamoxifen in the 1st-line treatment of patients with distant metastases. An overall survival benefit has not yet been demonstrated. Tamoxifen is superior to no endocrine therapy at all. Fulvestrant and toremifene are equivalent to tamoxifen in the first-line endocrine treatment of metastatic breast cancer [3]. There are several mechanisms of resistance that tumor cells can use to escape attempts to block their growth [4]. Enhancing the benefit of endocrine therapy by overcoming de novo or acquired resistance remains an important goal in sys-

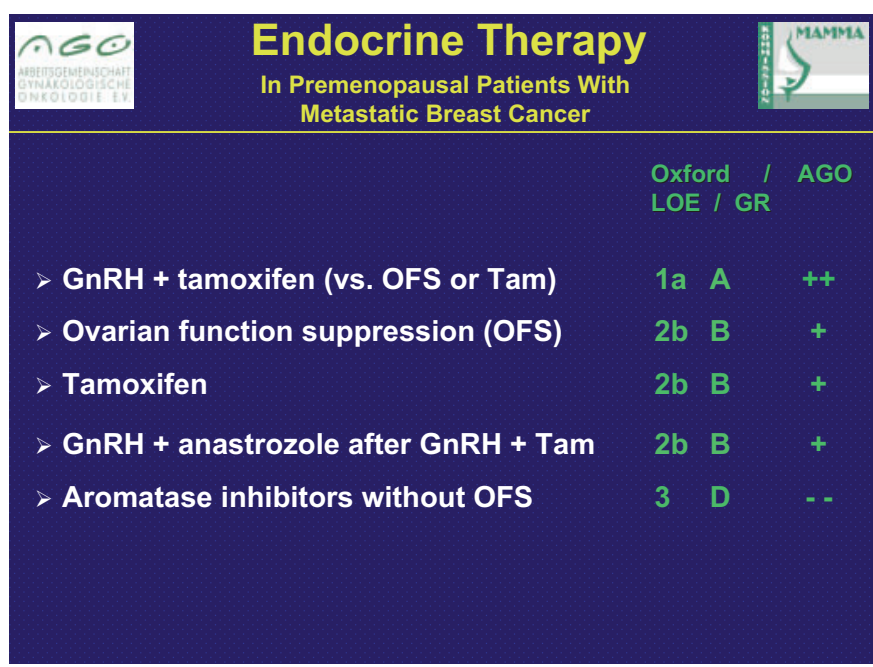

Fig. 1. Recommendations for endocrine therapy in premenopausal patients with metastatic breast cancer.

temic therapy of advanced breast cancer. Sequencing different endocrine steps may possibly sustain the endocrine responsiveness [5]. Otherwise, the increasing recognition of the roles of epidermal growth factor receptor (EGFR) and human EGFR2 (HER2) in cross-talk activation of ER signaling has led to studies aimed at identifying whether small-molecule tyrosine kinase inhibitors or monoclonal antibodies targeted against these receptors give additive or synergistic effects when combined with endocrine agents.

\section{Premenopausal Patients}

In premenopausal women with advanced breast cancer, the combination of LHRH (luteinizing hormone-releasing hormone) agonists plus tamoxifen is more effective than LHRH agonists or tamoxifen alone. Based on these data, the combination of an LHRH agonist plus tamoxifen is the recommended endocrine treatment in these patients [6]. If a patient shows tumor progression under this combination treatment and is still eligible for further hormonal treatment, she may benefit from ongoing ovarian suppression in combination with anastrozole [7]. Although there are no sufficient data regarding this situation, further ovarian function suppression accompanied by endocrine therapy similar to postmenopausal women is recommended (fig. 1).

\section{Postmenopausal Metastatic Breast Cancer}

\section{After Adjuvant Tamoxifen}

3rd-generation aromatase inhibitors (AIs) are the preferred 1st-line endocrine treatment in patients with recurrent disease progressing after or during adjuvant tamoxifen (fig. 2). In phase 3 trials, AIs were superior to tamoxifen in terms of re- 


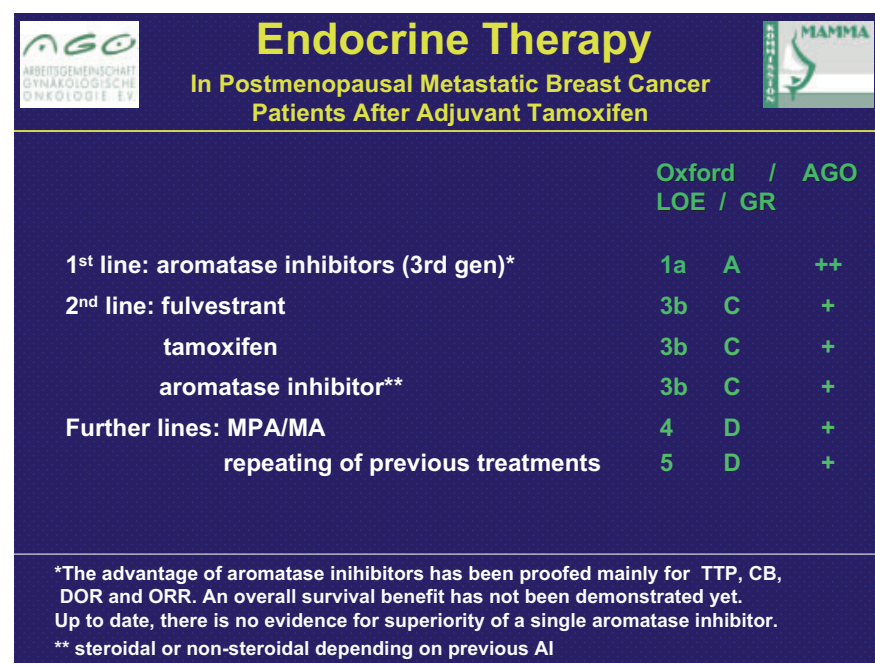

Fig. 2. Recommendations for endocrine therapy in postmenopausal metastatic breast cancer patients after adjuvant treatment with tamoxifen.

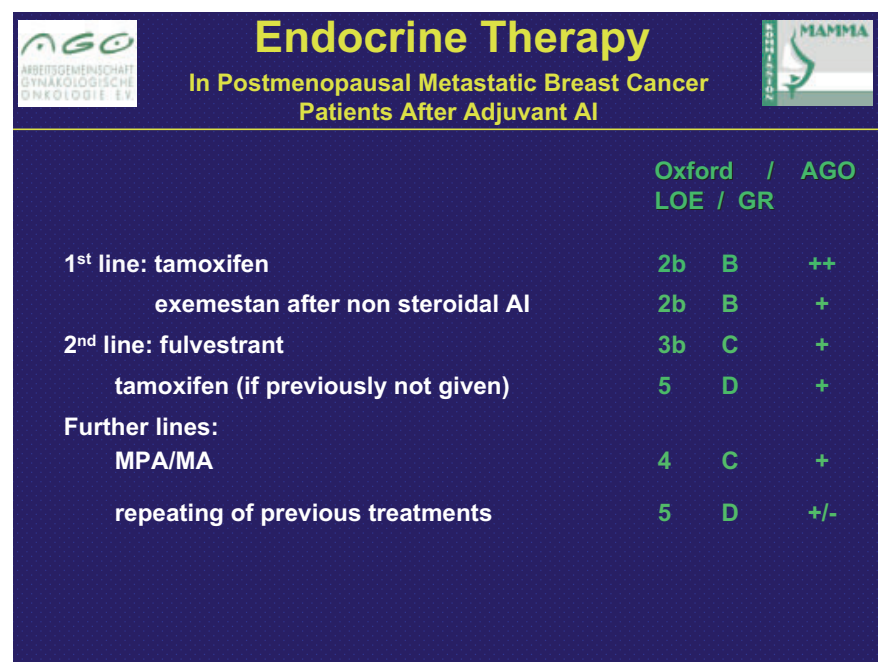

Fig. 3. Recommendations for endocrine therapy in postmenopausal metastatic breast cancer patients after adjuvant treatment with an aromatase inhibitor (AI).

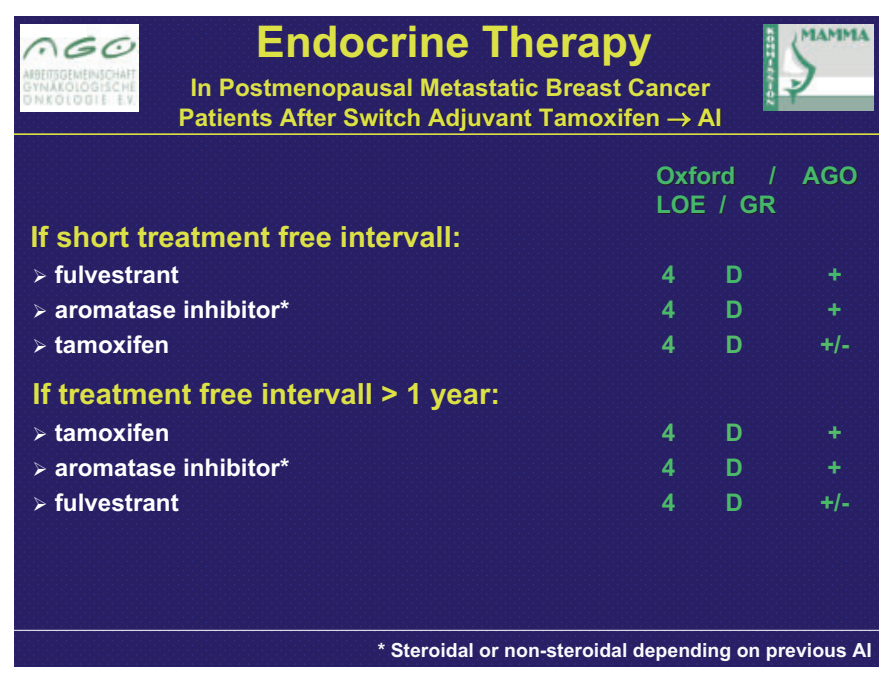

Fig. 4. Recommendations for endocrine therapy in postmenopausal metastatic breast cancer patients after switch from adjuvant tamoxifen to an aromatase inhibitor (AI). sponse rate, clinical benefit rate and time to progression. In second-line treatment, fulvestrant, a second AI or tamoxifen again are reasonable options. Steroidal AIs (exemestane) have shown activity after failure of non-steroidal AIs (letrozole, anastrozole) [8]. Vice versa, patients receiving exemestane as first anti-aromatase agent may also benefit from letrozole or anastrozole after disease progression [9]. There is a non-cross resistance between steroidal and non-steroidal antiaromatase agents. It is therefore assumed that the partial noncross resistance between steroidal and non-steroidal anti-aromatase agents is independent of the sequence employed. In phase III trials, fulvestrant has been shown to be at least as effective as the third-generation AI anastrozole in the treatment of postmenopausal women with advanced breast cancer progressing after prior tamoxifen therapy [3]. Fulvestrant is administered as a once-monthly $250 \mathrm{mg}$ intramuscular injection into the gluteus muscle. Compared with AIs and tamoxifen, fulvestrant is equally well tolerated [10]. Also, after progression during fulvestrant treatment, tumor cells may retain their endocrine sensitivity (mainly when patients showed a tumor response to the preceding treatment) so that other endocrine drugs have shown activity, even in heavily endocrinepretreated patients [5].

Because of their side effects, medroxyprogesterone acetate (MPA) and megestrol acetate (MA) are the last choice of endocrine treatment options. In patients treated with all available endocrine drugs, retreatment with previously applied agents may in some cases be a reasonable option. Selective ER modulators (SERMS), such as toremifene and raloxifene, have only poor efficacy following tamoxifen failure [11].

\section{After Adjuvant AI}

There are only few data regarding the efficacy of endocrine agents after progression during or following adjuvant AI treatment. Treatment options in this situation are tamoxifen (clinical benefit 50\%) [12] or a non-cross-resistant AI (25-44\%) (fig. 3) [8, 9]. Further treatment options are fulvestrant and MPA/MA.

\section{After Switching from Adjuvant Tamoxifen to AI}

As a result of the currently used switching of adjuvant endocrine treatment, this situation is new and will increase in the future. However, in postmenopausal women with advanced breast cancer and previous adjuvant tamoxifen and AI therapy, the treatment-free interval is an important issue. If relapse occurred during or shortly after switching, patients might benefit the most from fulvestrant or a non-cross resistant AI. It is assumed that patients who respond to fulvestrant could restore sensitivity to subsequent endocrine therapies [5]. If the treatment-free interval was 'long', tamoxifen, noncross resistant AI or fulvestrant are the treatment options. The level of evidence is however low, since there are only few retrospective data and so far no prospectively randomized trials dealing with these issues (fig. 4). 
Combination of endocrine and cytostatic therapy is not recommendable, because the combination induces rather increased toxicity and does not result in an improvement of disease-free interval or overall survival $[13,14]$. Thus, endocrine and cytostatic therapy should be performed as sequential treatment modalities. There are unfortunately no data on HER2-positive hormone receptor-positive patients regarding the value of the upfront combination of endocrine therapy and trastuzumab in metastatic breast cancer. Studies with the AIs anastrozole and letrozole \pm trastuzumab have been finished or are still ongoing.
There are only limited data about the effects of maintenance endocrine therapy following chemotherapy-induced response in hormone-sensitive tumors. Analyses by Berruti et al. [15] and Montemuro et al. [16] suggest a benefit in time to progression and overall survival for endocrine maintenance therapy. However, these are retrospective analyses so that the prognostic impact of maintenance endocrine therapy needs confirmation in randomized studies.

\section{References}

1 De Laurentiis M, Arpino G, Massarelli E, Ruggiero A, Carlomagno C, Ciardiello F, Tortora G D'Agostino D, Caputo F, Cancello G, Montagna E, Malorni L, Zinno L, Lauria R, Bianco AR, De Placido S: A meta-analysis on the interaction between HER-2 expression and response to endocrine treatment in advanced breast cancer. Clin Cancer Res 2005;11:4741-4748.

2 Linden HM, Stekhova SA, Link JM, Gralow JR, Livingston RB, Ellis GK, Petra PH, Peterson LM, Schubert EK, Dunnwald LK, Krohn KA, Mankoff DA: Quantitative fluoroestradiol positron emission tomography imaging predicts response to endocrine treatment in breast cancer. J Clin Oncol 2006;24:2793-2799.

3 Howell A, Robertson JF, Abram P, Lichinitser MR, Elledge R, Bajetta E, Watanabe T, Morris C, Webster A, Dimery I, Osborne CK: Comparison of fulvestrant versus tamoxifen for the treatment of advanced breast cancer in postmenopausal women previously untreated with endocrine therapy: a multinational, double-blind, randomized trial. J Clin Oncol 2004;22:1605-1613.

4 Normanno N, Di Maio M, De Maio E, De Luca A de Matteis A, Giordano A, Perrone F: Mechanisms of endocrine resistance and novel therapeutic strategies in breast cancer. Endocr Relat Cancer 2005;12:721-747.

5 Robertson JF, Howell A, Gorbunova VA, Watanabe T, Pienkowski T, Lichinitser MR: Sensitivity to further endocrine therapy is retained following progression on first-line fulvestrant. Breast Cancer Res Treat 2005;92:169-174.
6 Klijn JG, Blamey RW, Boccardo F, Tominaga T, Duchateau L, Sylvester R: Combined tamoxifen and luteinizing hormone-releasing hormone (LHRH) agonist versus LHRH agonist alone in premenopausal advanced breast cancer: a metaanalysis of four randomized trials. J Clin Oncol 2001;19:343-353.

7 Forward DP, Cheung KL, Jackson L, Robertson JF: Clinical and endocrine data for goserelin plus anastrozole as second-line endocrine therapy for premenopausal advanced breast cancer. Br J Cancer 2004;90:590-594.

8 Lonning PE, Bajetta E, Murray R, Tubiana-Hulin M, Eisenberg PD, Mickiewicz E, Celio L, Pitt P, Mita M, Aaronson NK, Fowst C, Arkhipov A, di Salle E, Polli A, Massimini G: Activity of exemestane in metastatic breast cancer after failure of nonsteroidal aromatase inhibitors: a phase II trial. J Clin Oncol 2000;18:2234-2244.

9 Bertelli G, Garrone O, Merlano M, Occelli M, Bertolotti L, Castiglione F, Pepi F, Fusco O, Del Mastro L, Leonard RC: Sequential treatment with exemestane and non-steroidal aromatase inhibitors in advanced breast cancer. Oncology 2005;69:471477.

10 Vergote I, Abram P: Fulvestrant, a new treatment option for advanced breast cancer: tolerability versus existing agents. Ann Oncol 2006;17:200-204.

11 Dodwell D, Wardley A, Johnston S: Postmenopausal advanced breast cancer: Options for therapy after tamoxifen and aromatase inhibitors. Breast 2006 (Epub ahead of print).

12 Thurlimann B, Robertson JF, Nabholtz JM, Buzdar A, Bonneterre J: Efficacy of tamoxifen following anastrozole ('Arimidex') compared with anastrozole following tamoxifen as first-line treatment for advanced breast cancer in postmenopausal women. Eur J Cancer 2003;39:2310-2317.
13 Sledge GWJ, Hu P, Falkson G, Tormey D, Abeloff M: Comparison of chemotherapy with chemohormonal therapy as first-line therapy for metastatic, hormone-sensitive breast cancer: An Eastern Cooperative Oncology Group study. J Clin Oncol 2000;18:262-266.

14 Australian and New Zealand Breast Cancer Trials Group: A randomized trial in postmenopausal patients with advanced breast cancer comparing endocrine and cytotoxic therapy given sequentially or in combination. The Australian and New Zealand Breast Cancer Trials Group, Clinical Oncological Society of Australia. J Clin Oncol 1986;4:186-193.

15 Berruti A, Zola P, Buniva T, Bau MG, Farris A Sarobba MG, Bottini A, Tampellini M, Durando A, Destefanis M, Monzeglio C, Moro G, Sussio M, Perroni D, Dogliotti L: Prognostic factors in metastatic breast cancer patients obtaining objective response or disease stabilization after first-line chemotherapy with epirubicin. Evidence for a positive effect of maintenance hormonal therapy on overall survival. Anticancer Res 1997;17:27632768

16 Montemurro F, Rondon G, Ueno NT, Munsell M, Gajewski JL, Champlin RE: Factors affecting progression-free survival in hormone-dependent metastatic breast cancer patients receiving highdose chemotherapy and hematopoietic progenitor cell transplantation: role of maintenance endocrine therapy. Bone Marrow Transplant 2002;29:861-866. 